\title{
Opinión pública, formación del consenso y propaganda en dictadura
}

Reseña de: Julia Risler (2018). La acción psicológica. Dictadura, inteligencia y gobierno de las emociones 1955-1981. Buenos Aires: Editorial Tinta Limón.

Daniel Lvovich

Universidad Nacional de General Sarmiento - CONICET, Argentina

daniel.lvovich@gmail.com

La acción psicológica, Dictadura, inteligencia y gobierno de las emociones, 1955-1981 representa un aporte fundamental para la comprensión de una dimensión de la última dictadura militar hasta ahora más intuida que estudiada. Se trata de una versión reelaborada de la tesis de doctorado en Ciencias Sociales de Julia Risler, defendida en la Universidad de Buenos Aires en 2015, titulada Acción psicológica, comunicación y propaganda durante la última dictadura argentina (1976-1983).

El libro se estructura en cuatro capítulos. El primero se ocupa de estudiar la génesis y desarrollo de la doctrina argentina de acción psicológica desde 1955, en diálogo con las doctrinas al respecto desarrolladas en Francia y Estados Unidos y con los cambiantes contextos políticos durante los cuales los instrumentos doctrinarios se desarrollaron a lo largo de más de dos décadas, hasta la etapa de la última dictadura. Según demuestra la autora, la doctrina de la Acción Psicológica se desarrolló en estrecha vinculación con la doctrina de guerra contrarrevolucionaria, ya que fue considerada como uno de los elementos de la estrategia total elaborada en respuesta a la hipótesis de conflicto permanente, propia de las guerras modernas desde el fin de la Segunda Guerra Mundial. Tanto la doctrina francesa como la norteamericana le asignaban un valor estratégico a los enfrentamientos surgidos en el marco de una guerra total en la cual la población se incorporaba como amenaza, y en donde todas las capacidades políticas y militares se empleaban en la guerra contrarrevolucionaria. En el caso argentino, ya desde 1958 en la obra del principal teórico local de la Acción Psicológica, el Coronel del Ejército Jorge Heriberto Poli, se planteaba que la guerra total requería una "nación en armas" que pudiera brindar una respuesta integral al conflicto, sin eximir a ninguna fuerza. Poli definía ya en ese año que el conflicto principal de la época residía en la pugna entre dos concepciones políticas e ideológicas, una "democrático-capitalista" y la otra "totalitario-comunista".

Desde 1966, distintos reglamentos militares que guiaban la acción contrarrevolucionaria enfatizaron en la centralidad de la acción psicológica a través de distintos instrumentos que lograran que la población apoyara las acciones militares y colaborara con ellas a través de denuncias. Entre esos instrumentos se encontraban los propios de la Acción Cívica de las Fuerzas Armadas, los de inteligencia y sobre todo la propaganda, a través de distintas vías, pero principalmente la que representaban los grandes medios de comunicación.

En el segundo capítulo, el libro de cuenta de la estrategia psicosocial de la última dictadura militar. La Acción Psicológica adquirió a partir del golpe el estatuto de estrategia psicosocial, a través de la conformación de un Sistema Nacional de Comunicación Social. Tanto la elaboración de la propaganda, como el control y la utilización de los medios de comunicación, se realizaron a través del despliegue de un plan sistemático que articuló la búsqueda y análisis de la información proveniente de las acciones de inteligencia a través de instituciones gubernamentales y castrenses.

Si antes del golpe de Estado la acción psicológica se dirigía al enemigo y la comunicación social a la población amiga, durante el régimen militar la figura del enemigo se amplió tanto que las fronteras se 
difuminaron, por lo que los vocablos empezaron a usarse en el lenguaje militar, de manera indiscriminada. "La equiparación entre los términos acción psicológica y comunicación social coincidió con la ampliación de la figura del enemigo, que según las FFAA se encontraba 'mezclado' entre la población” (p. 91).

El despliegue de esta estrategia psicosocial se cristalizó en la conformación de un organigrama que articuló la Secretaría de Información Pública, el Ministerio del Interior, la SIDE y los organismos de inteligencia del Ejército, en la producción de información y propaganda, en el control de los medios de comunicación, y en la regulación del comportamiento de la población. El sistema incluía dos funciones clave. Por un lado, la obtención y análisis de información para llevar adelante el proceso de comunicación social. Esta información provenía de dos niveles: la investigación social a través de sondeos y encuestas de opinión, y la elaboración de informes sobre medios de comunicación (inteligencia). Por el otro, la segunda función era la difusión de información pública a través de un Sistema Nacional de Comunicación. Este sistema estuvo sometido a un permanente escrutinio y evaluación de su eficacia e impacto en la opinión pública; a través de la realización de sondeos y encuestas de opinión donde se relevaron las actitudes, conductas y juicios sobre el desarrollo de acciones políticas, militares y económicas por parte del régimen.

De esta manera, Julia Risler muestra convincentemente el modo en que desde estas agencias estatales se emplearon los recursos de las ciencias sociales para conocer la opinión de la población y para influir sobre la misma, aunque, lamentablemente, son escasas las encuestas y sondeos a los que podamos acceder para dar cuenta del efectivo devenir de esas opiniones y del impacto comprobable de los instrumentos empleados por el régimen para ganar la adhesión de la población.

El tercer capítulo da cuenta de las modalidades gubernamentales de control de la prensa y regulación de la población. Para ello se analizan la agencias estatales encargadas de esas funciones (Secretaria de Información Pública, Subsecretaría del Interior y Secretaría de Informaciones del Estado), y las diversas estrategias y normativas para la orientación y control de los medios de prensa que, de todos modos, en buena medida se sumaron de un modo entusiasta a la empresa "antisubversiva”. El régimen militar desplegó en relación a los medios una política de control y censura para poder gobernar en un clima de consenso, utilizándolos a la vez como un espacio de construcción de un discurso oficial que eliminara otras voces. Si bien durante la dictadura el control de la información se convirtió en un instrumento orgánico fundamental de la lógica autoritaria, los instrumentos de esta política censora y coercitiva se remontaban hasta 1974. A ese corpus normativo de censura y prohibiciones, el régimen militar sumó otros modos de coerción como la elaboración de listas negras, las intervenciones militares a los medios, el procesamientos de directores de diarios, las detenciones o secuestros de periodistas e incluso su asesinato, junto a otros mecanismos invisibles de presión, como el envío de comunicados o notas, "sugerencias" oficiales, recomendaciones informales o amenazas.

El capítulo se completa con el estudio de las modalidades de medición y control de la opinión pública, incluyendo el análisis de la estructura de las encuestas y sondeos aplicados por la SIP y la SIDE, los informes sobre la situación psicosocial elaborados sobre esa base y los planes nacionales de comunicación social que derivaban de aquellos.

El último y más extenso capítulo del libro analiza la propaganda del régimen, que constituyó la principal herramienta de su estrategia psicosocial. La autora aúna con acierto bajo el concepto de propaganda tanto las publicidades con fines comerciales cuanto las propagandas gráficas y audiovisuales sin finalidad comercial, junto a titulares y notas de medios gráficos. Elaboradas desde distintos lugares de enunciación, estas diversas intervenciones contribuyeron a construir núcleos de sentido que ayudaron a legitimar al régimen de facto.

La autora organiza la gran cantidad de piezas de propaganda que se basa en dos grandes estrategias, a las que denomina "Ganar la guerra" y "Ganar la paz". La primera se desplegó durante la fase más represiva del régimen militar, y apuntó a lograr el apoyo y la adhesión de la población en la "lucha contra la subversión”. Una vez que el régimen consideró que esa lucha había sido ganada, se abrió una fase política mediante la cual el régimen militar buscó la participación e involucramiento de la población en el PRN, que se corresponde con la segunda de las estrategias de propaganda. 
La estrategia de "Ganar la guerra" buscaba la construcción de la legitimidad del régimen militar para lograr el apoyo de la población. La propaganda mostró una buena imagen de la acción gubernamental y la construyó como lo nuevo, en contraposición al pasado, y como la garantía de vuelta a la normalidad. Buscó la amplia adhesión de la población al régimen, y tuvo como marco la presencia de una amenaza permanente que funcionó como advertencia a la población de recibir castigos o sanciones ante las posibles formas de subversión. Apelaba a la restauración y garantía del mantenimiento de la seguridad de la población, con el fin de lograr su apoyo a la implementación del nuevo orden instalado por el régimen militar. Incluyó, para tales fines, la naturalización de la violencia emanada de la acción militar; el uso de un lenguaje belicista en las publicidades comerciales que hizo habitual su presencia en la vida pública; la biologización de la subversión y la reiterada prédica sobre la necesidad de erradicarla y eliminarla.

Por su lado, la estrategia de "Ganar la paz" se desplegó en dos grandes cadenas significantes que buscaron la refundación de la Nación Argentina: la primera apuntó a regular los valores, actitudes y comportamientos, interpelando de manera individual al "buen ciudadano". Este debía asumir su responsabilidad como tal, defendiendo los valores de la familia y la educación, comprometiéndose a cumplir con sus derechos y obligaciones, a fin de lograr un "cambio de mentalidad". La segunda se desplegó en torno a la búsqueda de cohesión de los ciudadanos en un nosotros definido como contraparte de un otro, caracterizado como una amenaza a la soberanía nacional. Aquí la población fue interpelada de manera colectiva, e incitada a participar en la defensa de la Nación movilizándose en convocatorias organizadas para tal fin. La movilización nacional se realizó ante las críticas externas y la amenaza de posibles injerencias extranjeras en la política interior del país (sobre todo a partir de la denuncia por violación de los derechos humanos) y, finalmente, ante la guerra, en donde se identificó un enemigo externo que funcionó como antagonista frente a la búsqueda de unión y cohesión nacional.

El libro de Julia Risler resulta un texto de consulta ineludible para quien decida estudiar el devenir de la estrategia de Acción Psicológica en los años de la dictadura. Sin duda, el libro resuelve con más éxito la presentación de los aspectos doctrinarios e institucionales del problema estudiado que el análisis de las prácticas que buscaron escrutar el estado de la opinión de los diversos grupos sociales e influir sobre su conducta, en gran medida debido a la dificultad para acceder a los documentos que permitan dar cuenta de esta dimensión, a excepción de las campañas publicitarias consideradas como fuentes. Los investigadores que logren avanzar en el examen y exposición de dichas prácticas, cuando el acceso a las fuentes lo permita, encontraran en esta obra un punto de partida sólido, inteligente y documentado. 